\title{
MOBILE TRAVEL SERVICES: THE EFFECT OF MODERATING CONTEXT FACTORS
}

\author{
H. BOUWMAN, $*$ C. CARLSSON, $\uparrow$ C. LOPEZ-NICOLAS, $\uparrow$ B. MCKENNA,, \\ F. MOLINA-CASTILLO, $\mid$ T. TUUNANEN,\# and P. WALDEN**
}

*Information and Communication Technology, Faulty of Technology, Policy and Management, Delft University of Technology, Delft, The Netherlands

$\dagger$ Institute for Advanced Management Systems Research, Åbo Akademi University, Åbo, Finland tDepartment of Management and Finance, University of Murcia, Campus de Espinardo, Murcia, Spain $\S$ Department of Information Systems \& Operations Management University of Auckland,

\section{Auckland, New Zealand}

\Department of Marketing, College of Economics and Business Administration, Universidad de Murcia, Campus de Espinardo, Murcia, Spain

\#Department of Information Processing Science, University of Oulu, Oulu, Finland

**Institute for Advanced Management Systems Research, Åbo Akademi University, Åbo, Finland

\begin{abstract}
This article has two objectives: (1) to draw an international comparison regarding the acceptance of mobile travel services in three countries with different profiles when it comes to travelling and mobile telecommunications, and (2) to extend relevant literature on mobile applications, more specifically travel services, by including context-related concepts, taking moderating factors like location, mobility of users, physical, and social context into account. Based on surveys that were carried out in 2009, structural equation modeling is used to identify differences in patterns in the use of mobile travel services and in the role of context-related variables. The conclusion of this article is that context-related factors, that is, mobility and (physical and social) context, have an impact on the relationship between the core concepts of Technology Acceptance Model (TAM) and Diffusion of Innovation (DoI) research. Many studies on the acceptance and use of mobile services indicate that a deep understanding is needed of individual, context-related, and technological characteristics and the way they interact. This is also highly relevant to the travel industry, which wants to utilize the opportunities provided by mobile technology.
\end{abstract}

Key words: Mobile travel services; Technology acceptance model; Structural equation modeling; Diffusion of innovation 


\section{Introduction}

Mobile technology has become increasingly important in society (Castells, Fernándèz-Ardèvol, Qiu, \& Sey, 2007). Mobile Internet services have a profound impact on almost every society in the world (IDATE, 2010). One of the industries that has been affected most dramatically by the emergence of the Internet is the travel and tourism industry (Buhalis, 2003; Middleton, Fyall, Morgan, \& Ranchhod, 2009), which has changed considerably over the last decade, with travel websites and portals replacing many travel agencies. Travel service providers, airlines, and other public and private transport companies, as well as the hospitality industry, have all adopted the Internet as a way of marketing and selling their services, while emerging mobile and Global Positioning System (GPS) technologies are likely to affect travel, navigation, and hospitality services even more in years to come. These technologies will bring the websites and portals involved even closer to customers, business travelers, and domestic and international tourists alike, offering location-aware and context-aware services. As pointed out by Buhalis (2003), tourism and technology go hand in hand. Meanwhile, mobile tourist applications and mobile personalized information or recommender systems for tourists and travelers are being developed (e.g., Ahas, Aasa, Roose, Mark, \& Silm, 2008; Carlsson \& Walden, 2010; Edwards, Blythe, Scott, \& Weihong-Guo, 2006; Kenteris, Gavalas, \& Economou, 2009; Meng, Poslad, \& Wang, 2009; Wan, 2009). Thus far, however, the number of studies that have examined the acceptance of mobile travel services is rather limited (Edwards et al., 2006; Eriksson \& Strandvik, 2009; Katsura \& Sheldon, 2008; Rasinger, Fuchs, \& Höpken, 2007; Riebeck, Stark, Modsching, \& Kawalek, 2008).

The aim of this article is to contribute to existing literature on mobile travel applications by examining to what degree consumers in three different countries (Finland, the Netherlands, and New Zealand) adopt mobile travel services and how the (differences in) adoption rates can be explained. In earlier studies, several models have been used to examine the adoption of mobile services. Most of them have been influenced predominantly by intention-based models that are rooted in cognitive psy- chology, including the Theory of Reasoned Action (TRA) (Fishbein \& Ajzen, 1975), the Theory of Planned Behavior (TPB) (Ajzen, 1991), and the Technology Acceptance Model (TAM) (Davis, 1989) and its extensions. The TRA is based on the notion that people's actual behavior is determined by their intention to behave in certain ways and that their intention is in turn influenced both by their own attitudes and by subjective factors (social influences). The TPB has been proposed as an extension to the TRA, with the aim of accounting for internal and external constraints (e.g., people's economic situation or experience with a specific service) on behavior (Nysveen, Pederson, \& Thorbjornsen, 2005). Finally, the TAM was developed to predict people's intention to use a technology based on their perception of its ease of use and usefulness (Davis, 1989; Venkatesh \& Davis, 2000; Venkatesh, Morris, Davis, \& Davis, 2003). The TAM model has been criticized for not taking user context into account (Bouwman \& van de Wijngaert, 2009; Tan, Foo, Goh, \& Theng, 2009), an oversight that this article is intended to remedy by including context-related concepts. More specifically, this article explores the moderating roles of (1) mobility, defined as being mobile, (2) physical context, defined as social standards and norms with regard to the use of mobile devices in specific locations, and (3) social settings, defined as either being alone or in other people's company.

In addition, this article focuses on how travel patterns in the three countries under examination influence the acceptance of mobile travel services. We look at mobile services, such as time tables for buses, trains, and flights, the reservation and purchase of tickets, the location of relevant places, etc. Differences in national geography, size, and distance affect people's travel habits, which in turn influence the adoption of mobile travel services. Finland's population, for instance, is concentrated in the southern part of the country, but due to the size of the country, travelers tend to stay at hotels (or other accommodations) on a regular basis. In the Netherlands, domestic travel is limited due to the country's smaller size. Because the country's economic activities are highly concentrated, traffic in the Western part of the country is intensive. New Zealand, on the other hand, is less densely populated, but the main economic activities are 
divided among two main islands. This means that both Finland and New Zealand have about the same size in terms of population and geography, which leads to similar domestic travel patterns, while in the Netherlands, despite the fact that it has a much higher population, travel distances are smaller.

When it comes to mobile telecommunications, Finland has long been the international forerunner, although it has gradually been losing ground to Asian countries like Japan, South Korea, and China (Netsize, 2010), and to the US, after the introduction of Blackberrys, iPhones, and Android. The "Nokia factor" and the focus on R\&D in the country's national policy arenas have played an important role in Finland's national economy (Häikkiö, 2001). Like Finland, the Netherlands and New Zealand have a deregulated and liberalized telecommunication regime, but they are lagging behind when it comes to the development of attractive mobile services. New Zealand in particular has been slow in rolling out $3 \mathrm{G}$ networks, with Telecom New Zealand, one of the country's two main providers, launching $3 \mathrm{G}$ as late as 2009 and suffering a series of highly publicized crashes in its first year. The comparison between the three countries with regard to the way their national inhabitants experience mobile travel services may shed light on the viability and feasibility of mobile travel services, taking national differences into account.

Based on the information discussed above, this article has two objectives: (1) to extend existing literature on the adoption of mobile applications, more specifically travel services, by including context-related concepts, and (2) to carry out an international comparison regarding the adoption of mobile travel services in three countries with significantly different profiles in terms of travel and mobile telecommunications. To realize these objectives, we begin by reviewing existing studies to develop our conceptual model, with a specific emphasis on the role of mobility, physical context, and social context. Next, the differences in people's travel behavior and attitudes towards mobile telecommunication is addressed in greater detail, after which the research approach and results are discussed. Finally, we present our conclusions and discuss the limitations and practical implications of this study.

\section{Literature Review}

\section{Technology Acceptance (TAM) Model}

Traditionally, three theories have been used to investigate the adoption of information technology adoption: the Theory of Innovation Diffusion (Rogers, 1995), the Technology Acceptance Model (Davis, 1989; Davis, Bagozzi, \& Warshaw, 1989), and the Theory of Planned Behavior (TPB) (Ajzen, 1991). The innovation diffusion theory postulates five determinants of technology adoption: relative advantage, complexity, compatibility, triability, and observability. This theory has also been used to explain M-commerce adoption in particular (Kleijnen, de Ruyter, \& Wetzels, 2007; Wu \&Wang, 2005). Moreover, some studies propose the integration of the innovation diffusion theory and TAM. Mallat, Rossi, Tuunainen, and Öörni (2009) propose a model to understand the adoption of $\mathrm{M}$ ticketing services, using the PU and PEOU from TAM, and compatibility and mobility from innovation diffusion theory.

TAM, which was developed to predict end-user acceptance of information systems within organizations, originated from the Theory of Reasoned Action (TRA) (Ajzen \& Fishbein, 1980), which argues that both people's attitude toward an action and subjective norms have an impact on behavioral intention, which in turn affects how people perform an action. The fundamental rationale of TAM is that the users of information technology base their actions on a rational decision. TAM proposes that usefulness and ease of use of a system (new hardware, software, etc.) are the most salient factors of a person's intention to use that system in workplace environments. The key difference between workplace and consumer contexts with respect to TAM is that, in the latter, a hedonic factor may be an important addition to the model (Dabholkar \& Bagozzi; 2002; Childers, Carr, Peck, \& Carlson, 2001).

\section{Hypotheses Development}

\section{Perceived Usefulness, Perceived Ease of Use, and Use of Mobile Travel Services}

With the proliferation of the Internet and e-commerce, researchers have adopted and adjusted TAM to demonstrate its empirical value to the new World Wide Web (WWW). In addition, research into peo- 
ple's intentions to use mobile devices and services has mainly been based on TAM (Nysveen et al., 2005). Mobile travel services are different from other mobile services, like GPRS, surveillance, and entertainment (Bouwman, Carlsson, MolinaCastillo, \& Walden, 2007), and include services like checking flight/train time tables, making a reservation/purchasing flight/train tickets, booking a hotel room, using personalized guide information and travel recommendation services, etc. The "always on" and portable characteristics of mobile devices and services allow customers to gather information and carry out transactions while they are on the move by using their Internet-enabled mobile devices (Mahatanankoon, Wen, \& Lim, 2005). In one of the few studies on the travelrelated adoption of mobile Internet, Ishii (2004) reports that only $10 \%$ of the overall use of mobile Internet use took place when respondents were travelling on a train or bus. This may be because travelers are more interested in GPS and viewing maps (Economides \& Grousopoulou, 2009), than they are in accessing services via mobile Internet. In addition, making reservations or researching alternative ways of traveling may be more fun in a leisure travel context rather than in a business travel context (Long, Clark, Schiffman, \& McMellon, 2003). If we ignore the characteristics of the specific service under study, as is normally done in TAM research, we will not obtain a valid conceptualization of the actual and future use of mobile service bundles (Bouwman et al., 2007). Differences in service attributes cannot be ignored and a model for understanding the adoption of mobile travel services as such is needed.

TAM contains three basic relationships that affect people's Behavioral Intention (BI) to adopt Information Technology: 1) Perceived Ease of Use (PEOU) leads to BI, 2) Perceived Usefulness (PU) leads to BI, and 3) PEOU leads to PU. These three basic links have been tested in several studies and have proven to have high validity when it comes to explaining the acceptance of different technological products and services. A simplified version of TAM has also been tested in the adoption of various mobile devices and services: mobile Internet (Cheong \& Park, 2005; Hong, Thing, \& Tam, 2006; Lu, Yao, \& Yu, 2005), mobile services (Nysveen et al., 2005), mobile healthcare systems (Wu, Wang, \& Lin, 2007), mobile games (Ha, Yoon, \& Choi,
2007), mobile banking (Luarn \& Lin, 2005), and mobile commerce (Wu \& Wang, 2005). However, to date, basic TAM concepts have not been frequently used to examine the adoption of mobile travel services: there are a few notable exceptions (Edwards et al., 2006; Eriksson \& Strandvik, 2009; Rasinger et al., 2007; Riebeck et al., 2008). Thus, we posit the following hypotheses:

H1: Perceived usefulness has a positive effect on the use of mobile travel services.

H2: Perceived ease of use has a positive effect on the use of mobile travel services.

H3: Perceived ease of use has a positive effect on perceived usefulness.

\section{Personal Innovativeness}

It has been argued that people's attitude towards mobile innovations is based on the concept of personal innovativeness (Agarwal \& Prasad, 1998; Lu, Liu, Yu, \& Wang, 2008; Yang, 2005). Agarwal and Karahanna (2000) define personal innovativeness in the information technology domain as an individual trait reflecting a willingness to try out any new technology (in this case advanced mobile services). Agarwal and Prasad (1998) have presented a definition of personal innovativeness that indicates that people's level of innovativeness can mediate the effects of their perception of IT-related adoption decisions, and thus plays an important role in the extent to which technology is adopted (Yi, Jackson, Park, \& Probst, 2006). Personal innovativeness has been used to predict the adoption levels of a wide variety of technological innovations (Yang, 2005). Specifically, personal innovativeness may influence a person's use of mobile phone services (Mao, Srite, Thatcher, \& Yaprak, 2005). Earlier studies indicate that personal innovativeness increases the rate of adoption of WAP services (Teo \& Pok, 2003). Additionally, Yang (2005) indicates that (general) consumer innovativeness is a useful predictor of a person's behavior when it comes to adopting mobile commerce. Applying these findings to advanced mobile services, we posit that:

H4: Personal innovativeness with regard to mobile technologies has a positive effect on the use of mobile travel services. 
Individuals with higher levels of personal innovativeness are expected to have a more positive attitude towards new technologies (Lewis, Agarwal, \& Sambamurthy, 2003). Personal innovativeness was initially proposed as a moderator of PU and was later reconceptualized as a direct determinant (Yi et al., 2006). Specifically, Agarwal and Prasad (1998) have found that personal innovativeness can improve people's PU of the World Wide Web, while Lewis et al. (2003) suggest that it has a direct and positive influence on the PU of Internet technologies. Earlier, Straub, Limayem, and Karahanna (1995) found that personal innovativeness has a direct positive effect on the PU and PEOU of IT. With regard to the adoption of mobile services, personal innovativeness, specifically when it comes to mobile technologies, may also enhance the PU. In their study into the adoption of wireless Internet via mobile technology, Lu et al. (2005) have found that people's personal innovativeness has a direct positive impact on PU and PEOU, while Mao, Srite, Thatcher, and Yaprak (2005) have theorized about a direct positive effect of PI on PU. Based on the results of these studies, we posit that:

H5: Personal innovativeness with regard to mobile technologies has a positive effect on perceived usefulness of mobile travel services.

H6: Personal innovativeness with regard to mobile technologies has a positive effect on perceived ease of use of mobile travel services.

Although TAM represents an early attempt to apply psychological factors to IS and the adoption of computer technology (Schepers \& Wetzels, 2007), recently there has been growing concern about its appropriateness and comprehensiveness, and it is increasingly seen as being too parsimonious (Venkatesh \& Davis, 2000) and incomplete (Teo \& Pok, 2003), as being more suitable to an organizational context than to everyday life (Nysveen et al., 2005b), and as being deterministic (McMaster \& Wastell, 2005) and tautological (Bouwman, van den Hoof, van den Wijngaert, \& van Dijk, 2005) in nature. In addition, it has been claimed that TAM is unable to account for social influences and is limited in its ability to explain user intentions (Bhattacherjee, 2000; López-Nicolás, Molina-Castillo, \& Bouwman, 2008). Schepers and Wetzels (2007) have presented a meta-analysis of TAM on the basis of 51 studies. Two of their main conclusions are that the original TAM relationships are confirmed, mostly based on structural equations modeling, and that the specific technology being studied has a significant moderating effect on user behavior, which means that advanced mobile services may be different from earlier technologies in terms of their acceptance, which would in turn imply that existing models regarding IT adoption, like TAM, may not apply to advanced mobile services in a consumer setting and that some modifications or combinations have to be made.

Existing studies also indicate that TAM may not be sufficiently suitable for an advanced analysis and evaluation of mobile services, because it depends to a large extent on the contextual conditions of the services (Amberg, Hirschmeier, \& Wehrman, 2004). Bouwman and van de Wijngaert (2009) have demonstrated that TAM models are too generic in nature to fully explain people's intention when it comes to using mobile technologies, because context-related factors as well as factors related to the tasks people intend to carry out appeared to be more relevant. TAM should be extended and complemented by including additional, context-related factors that may be especially significant to the adoption of mobile travel services. This article contributes to TAM by including context-related concepts. Although context is an essential factor in the adoption of mobile systems (Mallat et al., 2009; Tan et al, 2009), it has rarely been studied formally, with a few notable exceptions. In this article, the moderating effects of three context-related conditions with regard to hypothesis 1 (perceived usefulness in relation to actual use of mobile travel services) and hypothesis 6 (personal innovativeness in relation to actual use of mobile travel services) are examined in greater detail.

\section{Context Related Concepts: Mobility, Physical, and Social Context}

Due to their inherent design, mobile phones can be "always on" and taken everywhere (Mahatanankoon et al., 2005). The concepts of mobility and ubiquitous or nomadic computing refer to the movement of technologies, people, settings, etc. Mobile devices and services allow people to move around while maintaining access to relevant ser- 
vices and staying (socially) connected. Mobile computing provides access to information, communication, and services independent of time and place (Mallat et al., 2009), which is reflected in concepts like "anytime and anyplace." Kleinrock (1996) sees these concepts as the core dimensions of mobility. Although advanced mobile services may be accessed in a mobile or fixed context, mobile travel services are expected to be especially useful in a mobile rather than in a fixed context. As pointed out by Fishbein and Ajzen (1975), context is a moderating concept when it comes to the relationship between people's attitudes, beliefs, values, and behavioral intention. Mobility plays a moderating role in the relationship between personal innovativeness and the actual use of mobile travel services, as well as between perceived usefulness and the actual use of mobile travel services. We posit the following hypothesis:

H7: Mobility plays a moderating role in the relation between (1) personal innovativeness and use of mobile travel services, and (2) perceived usefulness and use of mobile travel services.

Mobile devices and applications are not only used when people are mobile but also as a replacement for fixed telephony, for instance in offices or at home. When the penetration of an advanced mobile technology reaches a substantial level, users may come to depend on it in their social interactions. Social information processing theory (Salancik \& Pfeffer, 1978) posits that attitudes and behavior regarding communication are determined by social context. According to this theory, people's perceptions of media characteristics, the requirements of the communication tasks to be performed, and their attitudes toward communication media are influenced by social standards (LópezNicolás et al., 2008), which limit people in their use of mobile devices and applications, for instance in meetings or public places like restaurants or trains, simply because the use of mobile devices and applications is considered less socially acceptable. Therefore, it makes sense to take location into account when examining the use of mobile applications in general, and mobile travel services in particular (Tan et al., 2009). The importance people attribute to the physical setting may have a moderating effect on the relationship between personal innovativeness and perceived usefulness on the one hand, and the actual use of mobile travel service. However, the direction of the effect is unclear. In some locations, (home, work) mobile handsets and applications are substituting wired devices and applications, while in other locations the use of mobile devices and applications may be considered unacceptable.

H8: The importance attributed to the use of a mobile application or device in a physical context plays a moderating role between (1) personal innovativeness and the use of mobile travel services, and between (2) perceived usefulness and the use of mobile travel services.

With regard to social context, mobile devices are predominantly used to interact with others. Venkatesh and Davis (2000) argue that, when important members of a person's social group believe a certain behavior is appropriate (e.g., using a certain technology), these people will tend to elevate their view within their peer group. Hong and Tam (2006) have argued that using mobile services that are widely accepted by group members can often be a way to maintain membership and secure support through increased interaction within the group. Because innovations create uncertainty, individuals who are generally uncomfortable with uncertainty tend to interact with their social network before making a decision ( $\mathrm{Lu}$ et al., 2005). Pedersen (2005) has also suggested that less innovative people may be influenced more by their peers. Peer pressure reduces the perceived risk of adopting a new technology (Teo \& Pok, 2003). Using an innovation is seen as a form of public consumption and it can be influenced significantly by friends and colleagues (Hong \& Tam, 2006). Hong et al. (2006) argue that using mobile services that are widely accepted by group members can often be a way of maintaining membership and secure support through increased interactions within the group. Overall, it would appear that social context can explain the adoption and use of advanced mobile services like mobile travel services. Tan et al. (2009) also emphasize the relevance of social context with regard to the adoption and use of mobile travel ser- 
vices. The relationship between personal innovativeness and perceived usefulness on the one hand, and actual use of mobile travel service is moderated by social context.

H9: Social context plays a moderating role between (1) personal innovativeness and (2) perceived usefulness on the one hand, and the use of mobile travel services.

The hypotheses are summarized in Figure 1.

\section{Three-Country Study}

The model presented in this study is tested on the basis of data collected in three countries. Before discussing the methodology in greater detail, we discuss the three countries we examined (Finland, the Netherlands, and New Zealand). The motivation for the choice of these three countries is the variation in population size, travel, and tourism behavior, both at a national and international level.
Although Finland is less densely populated than most other European countries, with only 15.7 inhabitants per $\mathrm{km}^{2}$, most of its 5.2 million inhabitants live in the southern part of the country, with about 1.2 million people living in greater Helsinki. The average commuting distance is $13 \mathrm{~km}$ and the average time people spend commuting is about 30 minutes. The most popular mode of transportation for commuting is by private car $(80 \%)$. Other options are public transport and, for longer distances, the railway. People travel between cities by public or private bus companies and airlines, as well as by a state-owned railway company. In addition, in the archipelago, people use the available ferries linking the many islands (www.liikenne turva.fi/www/fi/tilastot/liitetiedostot/Tyliikennet ilasto.pdf). During holidays and on business trips, 14 million domestic guests are registered, with an average stay of 2.7 nights (www.stat.fi, last retrieved April 27, 2010). Numerous mobile applications for travelers and tourists are available on the Finnish market and new applications are fre-

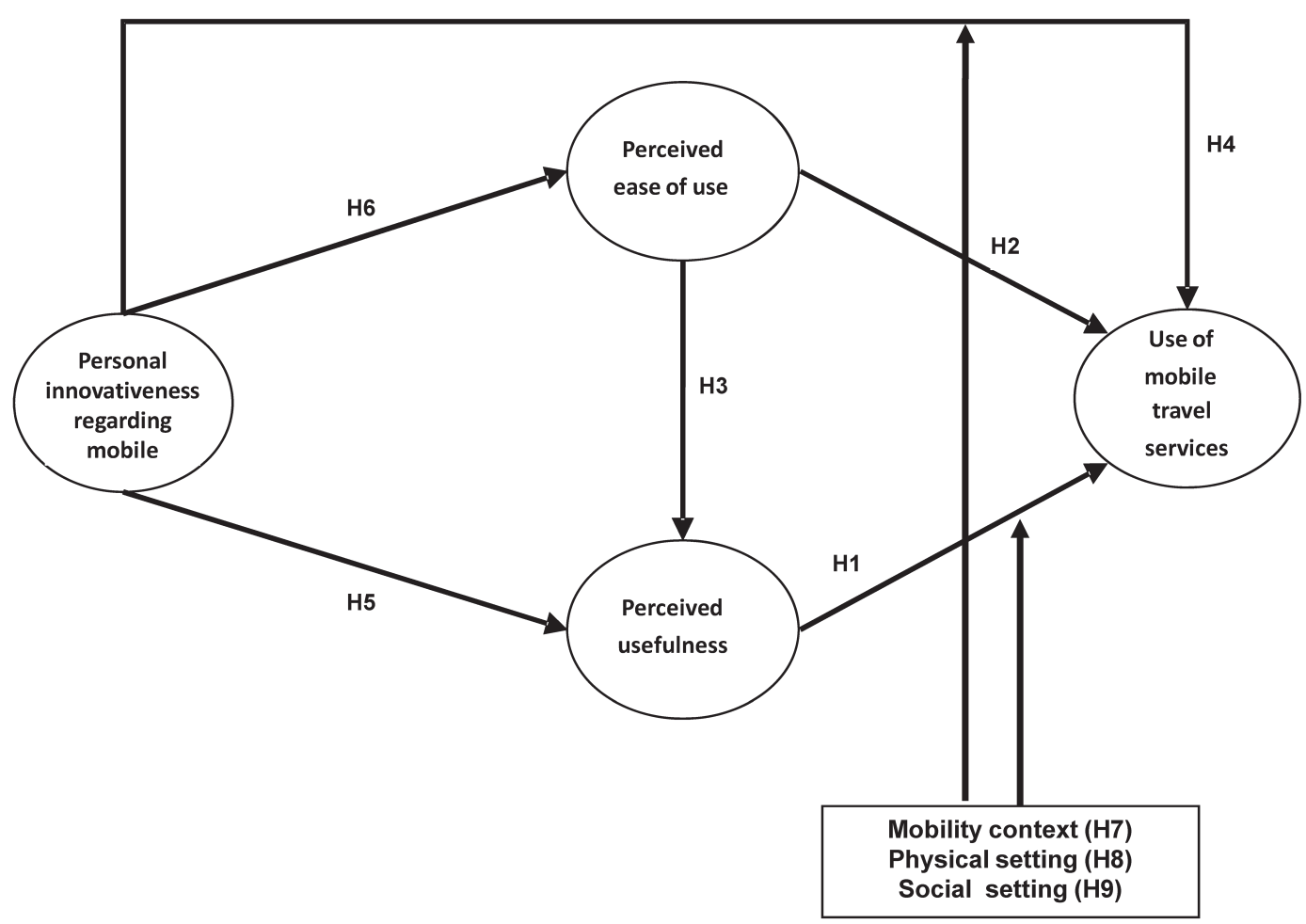

Figure 1. Conceptual model summarizing the main hypotheses. 
quently being introduced, such as real-time information about buses or trams (Mobile Guide for City Travelers as developed by VTT Technical Research Centre of Finland, see www.gizmag.com/ go/7320/, last retrieved April 27, 2010). Mobile booking services, bus and train ticket sales, checkin services, map services, weather forecasts, and traffic information, as well as general tourist information, are all available. In northern Finland, the Levi application (mobi.levi.fi) offers travelers various services, including information about skiing conditions.

For the Dutch, travel and hospitality services have only limited relevance, due to the short distances between the major economic centers, which are mainly concentrated in the western part of the country. The distance between the most Northern and most Southern cities is $334 \mathrm{~km}$ and takes approximately 3 hours by car. Problems travelers may encounter have to do with traffic jams. Public transport is dense and trains depart with a high frequency. The major cities are connected via train services that operate every 15 minutes. The average daily commuting time is 56 minutes. During holidays and on business trips, 18.5 million guests are registered, with an average stay of 1.8 nights (www.CBS.nl, retrieved March 13, 2010). Mobile applications that focus on travel and tourism are abundant in the Netherlands. There is a specific application for public transport planning. There are applications for real-time travel information, hotel reservations, flight reservations, location services, some of which are available via SMS-based services, while others have been specifically developed for Smart Phones.

New Zealand, by contrast, is a popular travel destination for people all over the world. Travelling from North to South on the two main islands takes several days by car, due to the fact that some 900-
$1000 \mathrm{~km}$ have to be covered. Driving tends to be slow due to speed limitations. It takes 1.5 hours to travel from Auckland to Dunedin by airplane on a direct route. All major cities offer public transport services, although with a frequency that is closer to the American model than it is to the European model, which means that private cars are the main means of transport. This can cause traffic jams, especially in the metropolitan area of Auckland, which has grown faster than expected. There is, however, a well-organized intercity bus service that is targeted at independent travelers of all ages. Renting a car is also relatively inexpensive. During holidays and on business trips, 18.7 million domestic guests are registered, with an average stay of 1.8 nights (www.stats.govt.nz, last retrieved April, 24, 2010). The official government website lists over 12,000 travel-related websites (www.linknz.co.nz).

Mobile applications that focus on travel and tourism have not really taken off in New Zealand, with a few exceptions, one of them being Vodafone Compass, which allows customers to use their mobile phone as a navigation device. Vodafone Live also offers SMS-based services that allow customers to find things nearby. Other examples are in-car navigation systems utilizing GPS, for example krusenz.com, which is a GPS audio device that broadcasts local information over the car's radio system. NZ Traffic is an application for iPhone that allows users to check local traffic conditions.

In light of the variation between the countries in population size, travel, and tourism behavior, it is interesting to see to what extent mobile travel services are being used. Next to the variation between the countries, there are also some commonalities. All three countries are part of the developed, Western style economies, and have populations that are willing to travel, for business and leisure, nationally and internationally.

Table 1

Basic Statistics on the Three Countries Included in the Study

\begin{tabular}{lccc}
\hline & Finland & New Zealand & The Netherlands \\
\hline Population & $5,311,000$ & $4,265,500$ & $16,475,750$ \\
Penetration of mobile phones & $143 \%$ & $112 \%$ & $117 \%$ \\
3G users & $2,675,000(50 \%)$ & $935,000(25 \%)$ & $4,612,000(33 \%)$ \\
ARPU & $€ 23$ & $€ 12,00$ & $€ 25$ \\
\hline
\end{tabular}




\section{Method}

This study is based on research that has been carried out since 2002 in Finland and since 2006 in the Netherlands. The research in New Zealand was carried out for the first time in 2009. The Finnish research has been leading, and the research in the Netherlands and New Zealand was designed to match the Finnish example. The approach to data collection was based on national experiences. Although we are aware that the results may be biased due to the way the information was collected, we started from the assumption that national researchers would be most informed about which data collection method, whether a web-based or a postal questionnaire, would be the most appropriate. The questionnaire was initially developed in Finland and tested in 2003-2005. In the following years, the questionnaire was also used and further developed by the Finnish and Dutch researchers. The questionnaire has been translated into English, Finnish, and Dutch, with all translations made in both directions for validation purposes.

\section{Sample and Data Collection}

The Finnish data were collected via a selfadministered questionnaire that was mailed to a sample of the Finnish population in the spring of 2009. The questionnaire has been used every year since 2002 and has been updated on a regular basis. The sample was selected from the electronic sampling frame provided by the Finnish Population Register Center. Random sampling was used, and the sample is representative of the Finnish population between 16 and 64 years. In all, 429 completed questionnaires were returned.

The Dutch respondents were selected from a large Internet panel of 25,000 households that are used regularly for survey research for multiple purposes. The panel is considered representative of the Dutch population. Potential respondents for this survey were first approached via telephone, to ask them whether they would be willing to participate. Respondents who agreed then received an e-mail with a link to the online questionnaire. From the 927 respondents that were approached, 524 returned a completed questionnaire. The sample was checked with regard to relevant criteria to ensure the sample was representative of the Dutch population of 18 years and older.

The New Zealand data were collected via a webbased questionnaire that was administered by a global commercial survey-sampling firm. Four hundred ninety-three completed questionnaires were returned, random sampling was used, and the sample is representative of the New Zealand population between 16 and 64 years.

\section{Questionnaire}

The questionnaire consists of three parts, the first of which contains questions about devices and subscriptions. In the second part, items are presented that have to do with personal innovativeness with regard to mobile technologies (see Appendix). The items referring to personal innovativeness have been used in Anckar and D'Incau (2002), Cheong and Park (2005), and Bouwman et al. (2007). The items concerning perceived usefulness and perceived ease of use are based on the items used in TAM research (see, for instance, López-Nicolás et al., 2008). The items are presented in the Appendix. The third part contains questions with regard to the actual and future use of 31 mobile services, as available on the Finnish, New Zealand, and Dutch markets. Five-point self-report scales were used, ranging from nonuse to (likely) intensive use. The services in question are explained extensively, to ensure that even people without experience with the services have a clear idea as to what they entail.

\section{Measurements and Scales}

The measures used in the model testing were refined by assessing their uni-dimensionality and reliability.

Confirmatory factor analysis (CFA) and composite reliability (SCR) were used to establish the required convergent validity, discriminate validity, and reliability. As can be seen in Table 2, the results of the factor models provide an acceptable fit. Because the research contains several multi-item reflective scales, the psychometric properties of the measures described above were analyzed using the scale composite reliability index (Bagozzi \& Yi, 1988) and the average variance extracted index (Fornell \& Larcker, 1986). Both indexes exceeded 
Table 2

Reliability and Correlation

\begin{tabular}{|c|c|c|c|c|c|c|c|c|}
\hline & Mean & SD & SCR & AVE & 1 & 2 & 3 & 4 \\
\hline \multicolumn{9}{|l|}{ Finland data } \\
\hline 1. Travel services & 1.63 & 0.92 & 0.87 & 0.65 & 0.81 & & & \\
\hline 2. Perceived usefulness & 2.81 & 0.93 & 0.88 & 0.63 & $0.31 *$ & 0.81 & & \\
\hline 3. Perceived ease of use & 3.07 & 1.04 & 0.92 & 0.74 & $0.16^{*}$ & $0.47 *$ & 0.86 & \\
\hline $\begin{array}{l}\text { 4. Personal innovativeness } \\
\chi^{2}(98)=405.47\end{array}$ & 1.95 & 0.95 & 0.87 & 0.62 & $0.38 *$ & $0.45^{*}$ & $0.31 *$ & 0.79 \\
\hline \multicolumn{9}{|c|}{$\begin{array}{l}\chi^{2}(98)=405.47 \\
\mathrm{CFI}=0.96, \mathrm{IFI}=0.96, \mathrm{NNFI}=0.95, \mathrm{RMSEA}=0.08\end{array}$} \\
\hline \multicolumn{9}{|c|}{ Netherlands data } \\
\hline 1. Travel services & 1.06 & 0.99 & 0.91 & 0.70 & 0.84 & & & \\
\hline 2. Perceived usefulness & 1.48 & 0.93 & 0.83 & 0.55 & $0.43 *$ & 0.74 & & \\
\hline 3. Perceived ease of use & 2.12 & 0.85 & 0.91 & 0.76 & $0.30^{*}$ & $0.43 *$ & 0.87 & \\
\hline 4. Personal innovativeness & .97 & 0.82 & 0.85 & 0.59 & $0.30^{*}$ & $0.60^{*}$ & $0.31 *$ & 0.77 \\
\hline \multirow{2}{*}{\multicolumn{9}{|c|}{$\begin{array}{l}\chi^{2}(98)=475.14 \\
\mathrm{CFI}=0.95, \mathrm{IFI}=0.95, \mathrm{NNFI}=0.94, \mathrm{RMSEA}=0.08\end{array}$}} \\
\hline & & & & & & & & \\
\hline \multicolumn{9}{|c|}{ New Zealand data } \\
\hline 1. Travel services & 1.24 & 0.58 & 0.86 & 0.61 & 0.78 & & & \\
\hline 2. Perceived usefulness & 3.59 & 0.71 & 0.85 & 0.60 & $0.32 *$ & 0.77 & & \\
\hline 3. Perceived ease of use & 3.78 & 0.73 & 0.93 & 0.77 & $0.23 *$ & $0.41^{*}$ & 0.87 & \\
\hline 4. Personal innovativeness & 2.86 & 0.91 & 0.88 & 0.64 & $0.36^{*}$ & $0.51 *$ & $0.36^{*}$ & 0.81 \\
\hline \multirow{2}{*}{\multicolumn{9}{|c|}{$\begin{array}{l}\chi^{2}(98)=309.17 \\
\mathrm{CFI}=0.97 . \mathrm{IFI}=0.97 . \mathrm{NNFI}=0.97 . \mathrm{RMSEA}=0.06\end{array}$}} \\
\hline & & & & & & & & \\
\hline
\end{tabular}

AVE, average variance extracted. The numbers on the diagonal are the square root of the AVE. Offdiagonal elements are correlations among constructs.

SCR, scale composite reliability: qc $=($ Aki $) 2 \operatorname{var}(n) /[($ Aki $) 2 \operatorname{var}(n)+$ Ahii]; $($ Bagozzi \& Yi, 1988)

AVE: qc $=($ Aki $) 2 \operatorname{var}(n) /[($ Aki) $2 \operatorname{var}(n)+$ Ahii $]$; (Fornell \& Larcker, 1986).

the recommended benchmark of 0.60 and 0.50 respectively.

\section{Multigroup Analysis}

The proposed model was tested via multigroup analysis. This procedure has been frequently used in various studies (Calantone, Garcia, \& Dröge, 2003; Coote, Forrest, \& Tam, 2006; Dayan \& Di Benedetto, 2010) and the steps taken to check for moderator effects are as follows. First, the items of each moderator constructs (mobility context, physical context, and social context) were summed to create a composite scale. Next, the sample was split into two groups, using median split, representing low/high levels of mobility context, high/low levels of physical context, and high/low levels of social context. A constrained model was estimated, in which all the parameters were held as invariant across the subsamples, after which an unconstrained model was estimated in which the structural paths were allowed to vary across the groups. Next, a chi-square difference test reveals whether the unconstrained model represents a significant improvement in fit over the constrained model. As hypothesized, the constrained models provided the best match with the data.

To test whether the measurement model is invariant among the three countries under study, a multigroup analysis was performed in which the unconstrained and constrained models were estimated simultaneously across groups. This procedure yielded a chi-square difference of $41.13(d f=$ $15)$ in the measurement weights, which is statistically nonsignificant $(p=0.07)$. The next constrained model in structural covariances produced a chi-square difference of $162.15(d f=131)$, which was statistically significant $(p=0.02)$. However, it is widely accepted that the equality of covariances represents an overly restrictive test of the data (Byrne, 2001). Thus, we concluded that the three models based on the respondents of the three countries are statistically invariant.

\section{Results}

The results show that adoption levels of mobile travel applications are highest in Finland, with the 


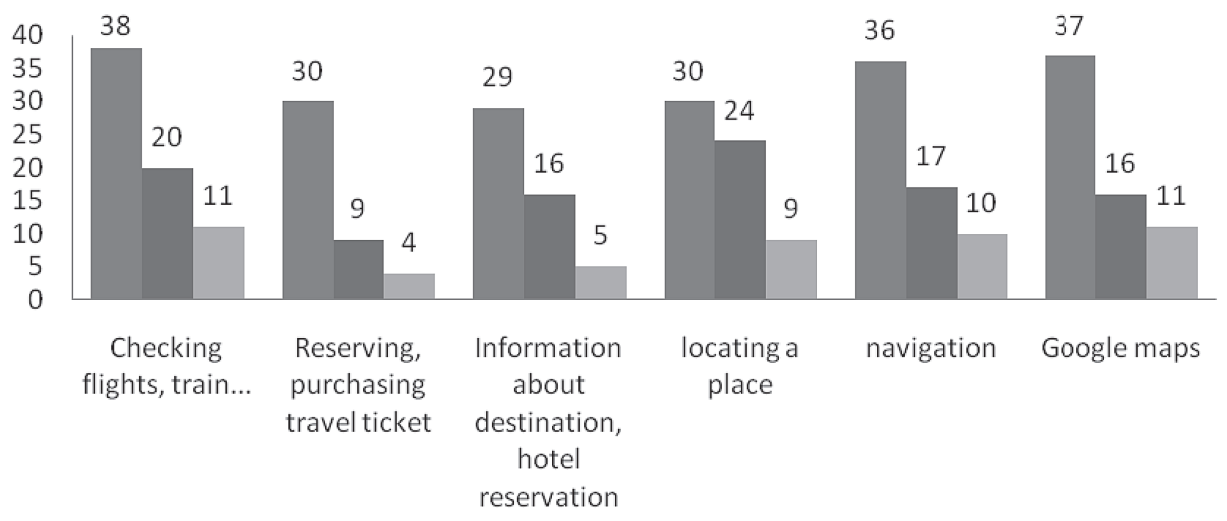

Finland $\quad$ New Zealand $\square$ Netherlands

Figure 2. Usage levels (\% of sample) for mobile travel services for the three countries.

Netherlands and New Zealand lagging behind (see Fig. 2).

The generic models (see Tables 3, 4, and 5) without moderating effects provide a good fit for all three countries. The explained variance in perceived usefulness is $32 \%$ for Finland and New Zealand, and $42 \%$ for the Netherlands.

However, the explained variance for the actual use of mobile travel services drops to $17 \%, 16 \%$, and $21 \%$, respectively. Personal innovativeness plays an important role in explaining the actual use directly or indirectly (i.e., mediated by the TAM concepts Perceived Ease of Use, and Perceived Usefulness). As far as the Netherlands are concerned, there is no direct relationship between personal innovativeness and the actual use of mobile travel services.

In our first analysis, we focused on moderating effects, which means that respondents indicate how important being able to use mobile services when mobile was to them. Next, we asked respondents to indicate how important being able to use mobile

Table 3

Results for Model Testing in Finland (MTS = Mobile Travel Services)

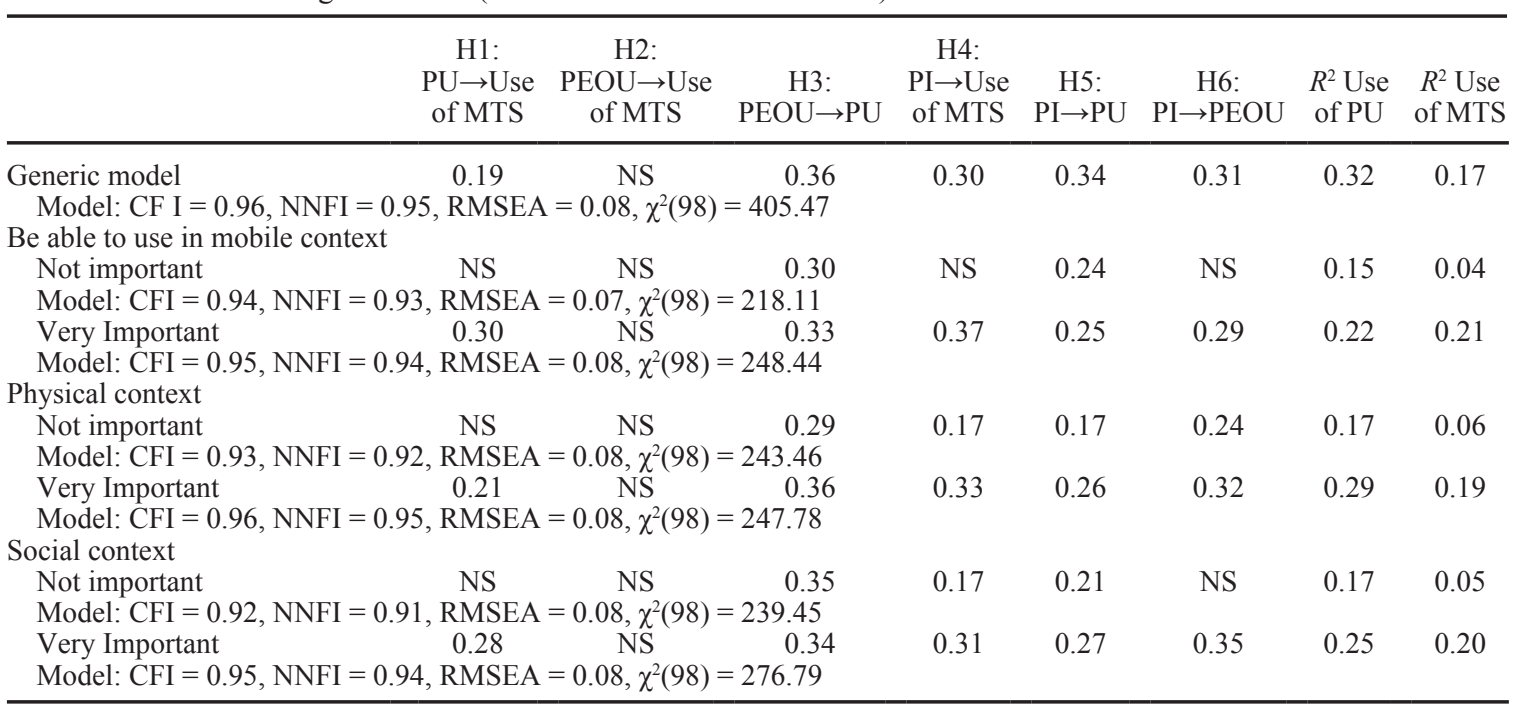


Table 4

Results for Model Testing in New Zealand (MTS = Mobile Travel Services)

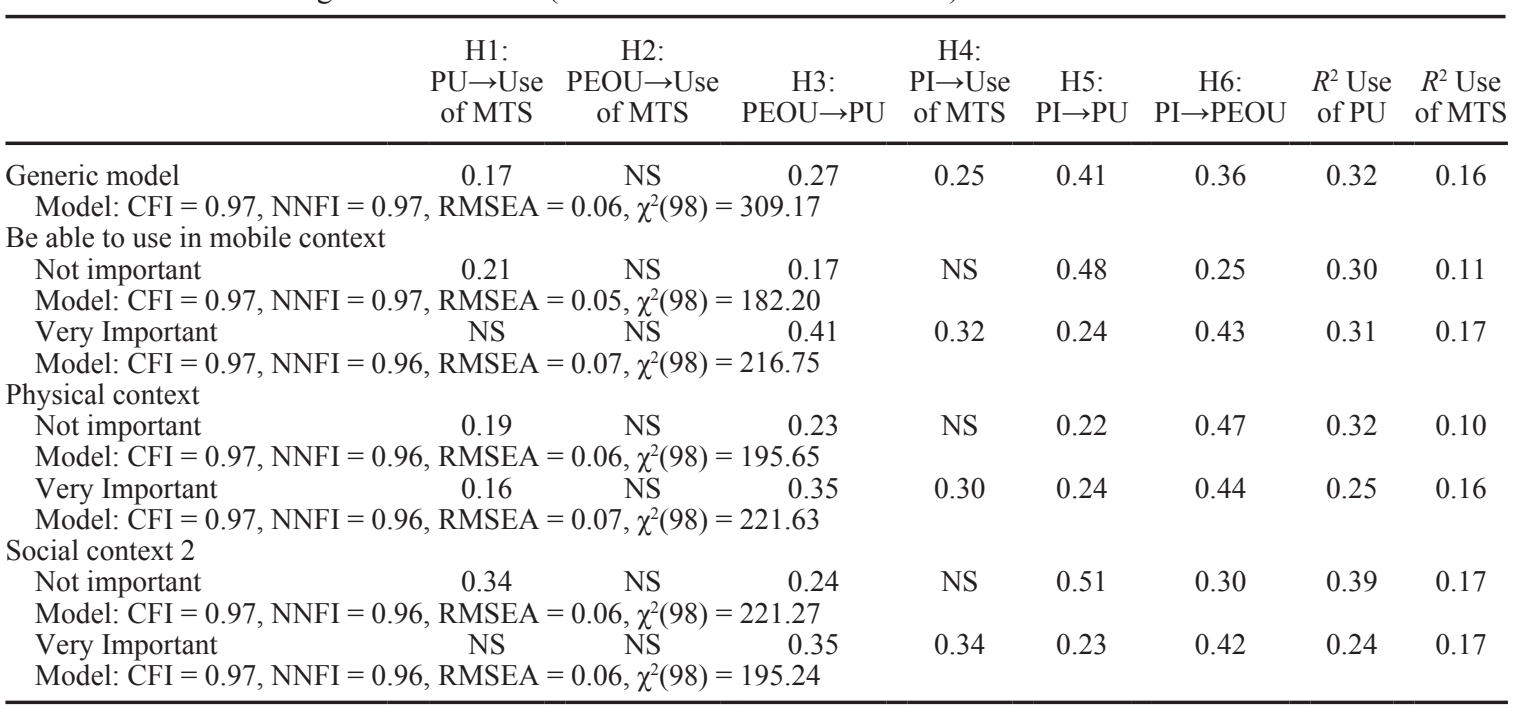

services in specific situations was to them. We then conducted a multigroup analysis in which we divided the respondents on the basis of the importance they attributed to social context. The analyses were carried out for the three countries separately. We discuss the results based on the hypotheses being tested.

The low explained variance for the models where we included moderating factors is striking. The explained variance of the other variables as included in the model lies between $15 \%$ and $39 \%$ for perceived usefulness, and between $4 \%$ and $21 \%$ for the use of mobile travel service. This indicates that, although people may claim they find some services useful, that does not mean they actually use them. As far as the Netherlands are concerned, only four of the six models could be tested, due to the fact (see Fig. 2) that mobile travel services are not used very extensively in the Netherlands. Secondly, it is striking that the models have either the same or, in

Table 5

Results for Model Testing in the Netherlands (MTS = Mobile Travel Services)

\begin{tabular}{|c|c|c|c|c|c|c|c|c|}
\hline & $\begin{array}{c}\text { H1: } \\
\text { PU } \rightarrow \text { Use } \\
\text { of MTS }\end{array}$ & $\begin{array}{c}\text { H2: } \\
\text { PEOU } \rightarrow \text { Use } \\
\text { of MTS }\end{array}$ & $\begin{array}{c}\mathrm{H} 3: \\
\mathrm{PEOU} \rightarrow \mathrm{PU}\end{array}$ & $\begin{array}{c}\text { H4: } \\
\text { PI } \rightarrow \text { Use } \\
\text { of MTS }\end{array}$ & $\begin{array}{c}\text { H5: } \\
\mathrm{PI} \rightarrow \mathrm{PU}\end{array}$ & $\begin{array}{c}\text { H6: } \\
\mathrm{PI} \rightarrow \mathrm{PEOU}\end{array}$ & $\begin{array}{l}R^{2} \mathrm{Use} \\
\text { of PU }\end{array}$ & $\begin{array}{l}R^{2} \text { Use } \\
\text { of MTS }\end{array}$ \\
\hline $\begin{array}{l}\text { Generic model } \\
\text { Model: } \mathrm{CFI}=0\end{array}$ & $\begin{array}{c}0.34 \\
\text { RMSEA }=\end{array}$ & $\begin{array}{c}0.13 \\
0.08, \chi^{2}(98)=\end{array}$ & $\begin{array}{l}0.28 \\
475.14\end{array}$ & NS & 0.51 & 0.31 & 0.42 & 0.21 \\
\hline \multicolumn{9}{|c|}{$\begin{array}{l}\text { Be able to use in mobile context } \\
\text { No fitting models }\end{array}$} \\
\hline \multicolumn{9}{|c|}{ Physical setting } \\
\hline Not important & 0.30 & 0.19 & 0.27 & NS & 0.43 & 0.25 & 0.32 & 0.06 \\
\hline \multicolumn{8}{|c|}{ Model: $\mathrm{CFI}=0.93, \mathrm{NNFI}=0.92, \mathrm{RMSEA}=0.08, \chi^{2}(98)=228.57$} & 0.14 \\
\hline \multicolumn{9}{|c|}{ Model: CFI $=0.94, \mathrm{NNFI}=0.93, \mathrm{RMSEA}=0.08, \chi^{2}(98)=243.46$} \\
\hline $\begin{array}{l}\text { Not important } \\
\text { Model: CFI = }\end{array}$ & $\begin{array}{l}0.35 \\
\text { RMSEA }=\end{array}$ & $\begin{array}{c}0.13 \\
0.08, \chi^{2}(98)=\end{array}$ & $\begin{array}{l}0.20 \\
302.65\end{array}$ & NS & 0.51 & 0.25 & 0.35 & 0.06 \\
\hline $\begin{array}{l}\text { Very Important } \\
\text { Model: CFI }=0\end{array}$ & $\begin{array}{c}0.28 \\
\text { RMSEA }=\end{array}$ & $0.08, \chi^{2}(98)=$ & $\begin{array}{l}0.34 \\
206.28\end{array}$ & NS & 0.27 & 0.35 & 0.34 & 0.05 \\
\hline
\end{tabular}


most cases, more explained variance for both perceived usefulness and the actual use of Mobile Travel Services (MTs) when mobility, physical, or social context are considered important. This demonstrates the moderating effects. Both in Finland and New Zealand, perceived usefulness and personal innovativeness are even more important explanatory factors when mobility, physical, or social context are taken in consideration. With regard to the relationship between Perceived Usefulness and the use of mobile travel services for mobility and physical context, Finland and New Zealand show opposite patterns. Whereas the relationship is nonsignificant in Finland in the notimportant condition, and weak in the important condition, the opposite is the case in New Zealand, which indicates that the relationship between context of use and the use of mobile travel services and the possible explanation of use warrants closer scrutiny. Thirdly, the lack of direct relevance of perceived ease of use in relation to the use of mobile travel services in most models is striking. Only the Dutch respondents apparently consider ease of use still an issue. In all other models the relation between perceived ease of use and actual use of mobile services is mediated by perceived usefulness.

\section{Discussion, Limitations, Managerial Implications, and Conclusions}

Although there are many applications that service business or leisure travelers, mobile travel services usage levels are still low. Research on the acceptance of mobile travel by consumers is rare, while a lot of effort is put into the development of new applications. Our literature review yielded no relevant studies, which is why, in this article, we explored the role of traditional concepts like personal innovativeness and TAM-related concepts in relation to the actual use of travel services. The hypotheses formulated in this article, with the exception of the hypothesis on the relationship between perceived ease of use and use of mobile travel services, are validated (see Table 6).

It is clear that traditional TAM is unable to explain the results of this study, because it only takes individual attitudes and perceptions into account, which is why, in this article, we also have examined the role of context for mobile (travel) services, and the results indicate that the nature of the (mobility, physical, or social) context moderates the use of the services. We need to understand the significance of context if we are to develop travel services that match people's needs and requirements (Tan et al., 2009). Existing studies into context-aware mobile travel services focus on topics that are either easy to understand (time of day, events, seasons of the year, specific user interest, location) or related to technological conditions (availability of networks, access to technology) (see Tan et al., 2009, for an extensive description). More difficult concepts, like mobility, physical, and social context, are less likely to be researched, which is why the results of this study are highly relevant. The need for the conceptualization of context, specifically in light of the mobile nature is broadly acknowledged (Basole, 2004; Bouwman \& van de Wijngaert, 2009; Kakihara \& Sørensen, 2001; Mallat et al., 2009).

Context clearly has a moderating effect, although the direction of the effect may vary. In Finland, the relevance of perceived usefulness with regard to explaining actual usage drops significantly, under the condition that mobility, physical, and social context are considered to be less relevant. We see the opposite in New Zealand. Also, as far as the relationship between personal innovativeness and the actual use of mobile travel services is concerned, we see that, although context is relevant, the effects in Finland and New Zealand are opposite, which may be explained by the fact that the services offered to Finnish customers are more varied and numerous compared to New Zealand. Another explanation may have to do with differences in social values with regard to the use of certain devices in particular locations and contexts. The fact that we found conflicting patterns in the three countries indicates that context-related research is very relevant to understanding why people adopt and use mobile services, including mobile travel services, and that context plays a different role in the three countries. More detailed research with regard to user context, beyond topics that are easy to classify, is needed. Conjoint analysis gives more precise and direct insight into the relevance of the context of people's behavior (Bouwman \& van de Wijngaert, 2002, 2009). On the other hand, the results make it clear that the broader context related 
Table 6

Results of Hypothesis Testing

Hypothesis

Generic Model

1 Perceived usefulness has a positive effect on use of mobile travel services.

2 Perceived ease of use has a positive effect on use of mobile travel services.

3 Perceived ease of use has a positive effect on perceived usefulness.

4 Personal innovativeness regarding mobile has a positive effect on perceived usefulness of travel mobile services

5 Personal innovativeness regarding mobile has a positive effect on perceived ease of use of mobile travel services

6 Personal innovativeness regarding mobile has a positive effect on the use of mobile travel services
Accepted

Rejected for Finland and New Zealand, accepted for the Netherlands

Accepted

Accepted

Accepted

Accepted to travel and tourism behavior, both national and international, also has to be considered. In that sense, the external validity of the framework is high, but specific contexts, at a national level, as well as at the level of direct usage, has to be carefully considered.

Although the immediate user context may be relevant, national idiosyncrasies play a role as well. Physical conditions within a country may significantly affect people's traveling habits and their actual need for mobile travel services. A densely populated country may benefit from detailed up-todate traffic information or information on public transport (delays), while a larger country may benefit more from information and booking applications involving flights and hotels.

Also, the relevance attributed to mobile communication may play a role. In Finland, conditions for the use of mobile travel services (for instance, the penetration of $3 \mathrm{G}$ phones and the abundant availability of applications) are more positive, due to a national commitment to mobile technology. Although the difference in the regulatory regimes of the various (European) countries are becoming smaller, they may still explain the differences in user patterns regarding the services examined in this article. In addition, there may be cultural differences. To examine this, we would need a multilevel research approach with clearly defined national characteristics (physical conditions, telecommunication regulation, market drivers) on the one hand, and consumer characteristic and behavior on the other.

With regard to practical implications, the providers of mobile travel services have to be aware that the services they offer are mainly supportive in nature (i.e., they help travelers find their way and provide relevant travel information). One of the main impediments in this regard is the lack of opportunities for real transactions via the mobile phones. Dealing with e-forms and providing credit card information via mobile phones still requires a great deal of effort. Users will prefer to use the Internet for concluding transactions with hotels, airlines, and car rentals, which means that mobile travel service providers have to focus on providing information, support, and after-sales services.

Developers of mobile applications for travelers need to understand the complexity of more socially embedded contexts and move away from the obvious and simple context that is currently being built into context-aware applications. As mentioned above, conjoint analysis can provide more detailed insight into user requirements that transcend the obvious. Attention needs to be paid to preferences, characteristics, and behavior, the specific tasks, ranging from information retrieval on travel destinations, to the execution of real transactions in booking trips users want to perform. It is important to analyze user behavior in different types of context, both at an abstract and at a specific level.

Although, as mentioned above, this article has some limitations, we contribute to existing literature by: (1) conducting an international comparison of the acceptance of mobile travel services in three countries that have significantly different profiles with regard to travel and mobile telecommunications, and (2) extending the technology acceptance literature on mobile applications, more specifically travel services, by including context-related con- 
cepts that are relevant from a traveling perspective. The effect of context on behavior (e.g., mobility, physical, and social context) is relevant to understanding why people use mobile travel applications. Its moderating effect is, however, not easy to establish, especially as the direction varies for the three countries. It is clear that the research presented in this article leaves open a number of highly relevant questions with regard to the acceptance and use of mobile technology, and the role of context. If we are to understand user patterns involving mobile travel services, we need to look at individual people, their context, the technology they use, and the way they interact. We need to understand how technology matches people's day-to-day travel-related activities in a way that takes their personal preferences and attitudes, as well as their specific physical and social context, into account.

\section{Biographical Notes}

Harry Bouwman is associate professor at Delft University of Technology, Faculty of Technology, Policy, and Management, Section Information and Communication Technology and a Finnish Distinguished Professor at Åbo Akademi University. He is author and editor of several books in the field of Multimedia, ICT, and Telecommunications. He has contributed to national and international scientific and business journals.

Christer Carlsson, Director of the Institute for Advanced Management Systems Research, and a professor of management science at Abo Akademi University in Abo, Finland. $\mathrm{He}$ is a Fellow of the IFSA and on the SG of the European Center for Soft Computing. He has lectured extensively at various universities in Europe, the US, Asia, and Australia. $\mathrm{He}$ is on the editorial board of several journals and the author of 4 books, an editor or coeditor of 5 special issues of international journals; he has published more than 250 articles.

Carolina López-Nicolas is an Assistant Professor in the Department of Management and Finance at the University of Murcia, Spain. She has been a Visiting Professor at Delft University of Technology in the Netherlands and Michigan State University in US. Her current research relates to knowledge management, information systems, business strategy, and mobile communications. She has published on these topics in such journals as Information \& Management, International Journal of Information Management, Technological Forecasting \& Social Change, Journal of Knowledge Management, International Journal of Internet Marketing and Advertising, and Journal of Enterprise Information Management.
Brad McKenna is a Ph.D. student and instructor at the University of Auckland, New Zealand. His research interests are in the areas of Usability, Design, and Assessment of Mobile Services, Information Systems Development, LocationBased Services, and User Interface Design.

Francisco José Molina-Castillo is assistant Professor in Marketing at the University of Murcia. He obtained a European Ph.D. and a master's degree on International Marketing in this University, a B.A. in Business Administration (University of Murcia) and B.A. in Accounting \& Finance in Europe (Manchester Metropolitan University). He has published in journals such as Industrial Marketing Management, Information \& Management, International Journal of Information Management, and International Journal of Internet Marketing and Advertising, among others. Since 2008, he has been secretary of the Spanish Marketing Association (AEMARK).

Tuure Tuunanen is a Senior Research Fellow in the Department of Information Processing Science at the University of Oulu. He is also a global faculty fellow of the Center for Service Leadership at ASU. He holds a D.Sc. (Econ) from the Helsinki School of Economics. His current research interests lie in the areas of information systems development methods and processes, service engineering, and IT enabled services. Dr. Tuunanen is the editor-in-chief of Journal of Information Technology Theory and Application (JITTA). For details on his research, please see http://www.tuunanen.fi

Pirkko Walden, Deputy Director of the Institute for Advanced Management Systems Research (IAMSR), Leader of the TUCS Mobile Commerce Laboratory, is a professor of marketing and information systems at Åbo Akademi University. She has published 2 monographs, 2 edited books, and more than 100 articles in journals and conference proceedings. Her primary research interests are focused on electronic and mobile commerce.

\section{Appendix}

\section{Travel Services:}

- Checking flight, train and/or bus timetables via a Mobile phone

- Reserving and/or purchasing flight, train or bus tickets

- Reading information about travel destinations and/or making reservation for accommodation via a Mobile phone

- Locating a place (office, café, hotel, etc.) via a Mobile phone

(score: never used-daily used)

Perceived Usefulness: 
- With mobile services I get information I need wherever and whenever

- With Mobile services I can carry out tasks wherever and whenever

- Advanced Mobile services make me more efficient

- With Mobile services I can coordinate tasks wherever and whenever

(score strongly agree-strongly disagree)

Perceived Ease of Use:

- I know how to use Mobile services

- Learning how to use Mobile services is easy for me

- Seems easy to me to learn how to use Mobile services

- It seems to me that using Mobile services is easy (score: strongly agree-strongly disagree)

Personal Innovativeness Mobile Technologies:

- I want my Mobile device, e.g. a Mobile phone, to be the latest model

- I prefer to buy a more expensive Mobile phone with new features instead of a cheaper Basic Mobile phone.

- I want to be among the first one to try out new Mobile services

- My Mobile phone has to be the latest model.

(score: strongly agree-strongly disagree)

Mobility Context (mobile):

How important to be able to use mobile services in certain locations (not important at all-to very important)

- On the road

- On a business trip

- On a train/bus

- On vacation

Physical Context (fixed):

How important is to be able to use mobile services in certain locations

- In public places

- At home

- At work

- In a meeting

- Doing my job

(score: not important at all-to very important)

Social Setting:

How important to use mobile services

- When in company of others

- Being alone
- When among family

(score: not important at all-to very important)

\section{References}

Agarwal, R., \& Karahanna, E. (2000). Time flies when you're having fun: Cognitive absorption and beliefs about information technology usage. MIS Quarterly, 24(4), 665-694.

Agarwal, R., \& Prasad, J. (1998). A conceptual and operational definition of personal innovativeness in the domain of information technology. Information Systems Research, 9(2), 204-215.

Ahas, R., Aasa, A., Roose, A., Mark, Ü., \& Silm S. (2008). Evaluating passive mobile positioning data for tourism surveys. An Estonian case study. Tourism Management, 29(3) 469-486.

Ajzen, I. (1991). The theory of planned behavior. Organizational Behavior and Human Decision Processes, 50(2), 179-211.

Ajzen, I., \& Fishbein, M. (1980). Understanding attitudes and predicting social behavior. Englewood Cliffs, NJ, Prentice-Hall.

Amberg, M., Hirschmeier, M., \& Wehrman, J. (2004). The Compass Acceptance Model for the analysis and evaluation of mobile services. International Journal of Mobile Communications, 2(3), 248-259.

Anckar, B., \& D'Incau, D. (2002). Value creation in mobile commerce: Findings from a consumer survey. Journal of Information Technology Theory \& Application, 4(1), 43-64.

Bagozzi, R. P., \& Yi, Y. (1988). On the evaluation of structural equation models. Journal of the Academy of Marketing Science 16, 74-94.

Basole, R. C. (2004). The Value and impact of mobile information and communication technologies. Proceedings of the IFAC Symposium on Analysis.

Bhattacherjee, A. (2000). Acceptance of e-commerce services: The case of electronic brokerages. IEEE Transactions on Systems, Man, and Cybernetics, 30(4), 411-420.

Bouwman, H., Carlsson, C., Molina-Castillo, F. J., \& Walden, P. (2007). Barriers and drivers in adopting actual and future mobile services in Finland. Telematics \& Informatics, 24(2), 145-160.

Bouwman, H., van den Hooff, B., van den Wijngaert, L., \& van Dijk, J. (2005). Information and communication technology in organizations. Sage: London.

Bouwman, H., \& van de Wijngaert, L. (2002). Content and context: A new research approach to the basic characteristics of information needs. New Media \& Society, 4(3), 329-353.

Bouwman, H., \& van de Wijngaert, L. (2009). Coppers context, and conjoints: A reassessment of TAM. Journal of Information Technology, 24(2), 186-201.

Buhalis, D. (2003). eTourism-Information technology for strategic tourism management. Edinburg Gate: Pearson Education Limited.

Byrne, B. M. (2001). Structural equation modeling with 
AMOS: Basic concepts, applications, and programming. Hillsdale, NJ: LEA publishers.

Calantone, R., Garcia, R., \& Dröge, C. (2003). The effects of environmental turbulence on new product development strategy planning. Journal of Product Innovation Management, 20(2), 90-103.

Carlsson, C., \& Walden, P. (2010). Supporting tourists at the Bomarsund fortress with a mobile value service. Journal of Information Technology Theory and Application, 11(1), 43-56.

Castells, M., Fernández-Ardèvol, M., Qiu J. L., \& Sey, A. (2007). Mobile Communication and Society. Cambridge, MA: The MIT Press.

Cheong, J. H., \& Park, M. C. (2005). Mobile internet acceptance in Korea. Internet Research, 15(2), 125-140.

Childers, T. L., Carr, C. L., Peck J., \& Carson, S. (2001). Hedonic and utilitarian motivations for online retail shopping behavior. Journal of Retailing, 77(4), 511-535.

Coote, L., Forrest, E., \& Tam, T. (2006). An investigation into commitment in non-western industrial marketing relationships. Industrial Marketing Management, 32(7), 595-604.

Dabholkar, P. A., \& Bagozzi, R. P. (2002). An attitudinal model of technology-based self-service: Moderating effects of consumer traits and situational factors. Journal of the Academy of Marketing Science, 30(3), 184-201.

Dayan, M., \& Di Benedetto, C. (2010). The impact of structural and contextual factors on trust formation in product development teams. Industrial Marketing Management, 39(4), 691-703.

Davis, F. D. (1989). Perceived usefulness, perceived ease of use and user acceptance of information technology. MIS Quarterly, 13(3), 319-40.

Davis, F. D., Bagozzi, R. P., \& Warshaw P. R. (1989). User acceptance of computer technology: A comparison of two theoretical models. Management Science, 35(8), 982-1003.

Economides, A. A., \& Grousopoulou, A. (2009). Students' thoughts about the importance and costs of their mobile devices' features and services. Telematics and Informatics 26(1), 57-84.

Edwards, S. J., Blythe, P. T., Scott, S., \& Weihong-Guo, A. (2006). Tourist information delivered through mobile devices: Findings from the image project. Information Technology \& Tourism, 8(1), 31-46.

Eriksson, N., \& Strandvik, P. (2009). Possible determinants affecting the use of mobile tourism services. In J. Filipe \& M. S. Obaidat (Eds.), e-Business and Telecommunications (Vol. 48, part 2, pp. (61-73). New York: Springer.

Fishbein, M., \& Ajzen, I. (1975). Beliefs, attitude, intention and behavior: An introduction to theory and research. Reading, MA: Addison-Wesley.

Fornell C. D., \& Larcker, F. (1986). Evaluation structural equation models with unobservable variables and measurement error. Journal of Marketing Research, $18,39$.

Ha, I., Yoon, Y., \& Choi, M. (2007) Determinants of adoption of mobile games under mobile broadband wireless access environment. Information \& Management, 44(3), 276-286.

Hong, S. H., \& Tam, K. (2006). Understanding the adoption of multipurpose information appliances: The case of mobile data services. Information Systems Research, 17(2), 162-179.

Hong, S. H., Thong, J., \& Tam, K. (2006). Understanding continued information technology usage behavior: A comparison of three models in the context of mobile internet. Decision Support Systems, 42(3), 1819-1834.

Häikkiö, M. (2001). Nokia, the inside story. London: Pearson, Edita.

IDATE. (2010). DigiWorld Yearbook 2010. Montpellier: Author.

Ishii, K. (2004). Internet use via mobile phone in Japan. Telecommunications Policy, 28, 43-58.

Kakihara, M., \& Sørensen, C. (2001). Expanding the 'mobility' concept. ACM SIGGROUP Bulletin, 22(3), 33-37.

Katsura, T., \& Sheldon P. (2008). Forecasting mobile technology use in Japanese tourism. Information Technology \& Tourism, 10(3), 201-214.

Kenteris, M., Gavalas, D., \& Economou, D. (2009). An innovative mobile electronic tourist guide application. Personal and Ubiquitous Computing, 13(2), 103-118.

Kleijnen, M., de Ruyter, K., \& Wetzels, M. (2007). An assessment of value creation in mobile service delivery and the moderating role of time consciousness. Journal of Retailing, 83(1), 33-46.

Kleinrock, L. (1996). Nomadicity: Anytime, anywhere in a disconnected world. Mobile Networks and Applications, 1(4), 351-357.

Lewis, W., Agarwal, R., \& Sambamurthy, V. (2003). Sources of influence on beliefs about information technology use: An empirical study of knowledge workers. MIS Quarterly, 27(4), 657-678.

Long, M. M., Clark, S. D., Schiffman, L. G., \& McMellon C. (2003). In the air again: Frequent flyer relationship programmes and business travellers' quality of life. International Journal of Tourism Research, 5, 421-432.

López-Nicolás, C., Molina-Castillo F. J., \& Bouwman, H. (2008). An assessment of advanced mobile services acceptance: Contributions from TAM and diffusion theory models. Information \& Management, 45(6), 359364.

Lu, J., Liu, C., Yu, C. S., \& Wang, K. L. (2008). Determinants of accepting wireless mobile data services in China. Information and Management, 45(1), 52-64.

Lu, J., Yao, J., \& Yu, C. (2005). Personal innovativeness, social influences and adoption of wireless Internet services via mobile technology. Journal of Strategic Information Systems, 14(3), 245-268.

Luarn, P., \& Lin, H. (2005). Toward an understanding of the behavioral intention to use mobile banking. Computers in Human Behavior, 21(6), 873-891.

Mahatanankoon, P., Wen, H. J., \& Lim, B. (2005). Consumer-based m-commerce: Exploring consumer perception of mobile applications. Computer Standards and Interfaces, 27(4), 347-357. 
Mallat, N., Rossi, M., Tuunainen, V. K., \& Öörni, A. (2009). The impact of use context on mobile services acceptance: The case of mobile ticketing. Information \& Management, 46(3), 190-195.

Mao, E., Srite, M., Thatcher, J., \& Yaprak, O. (2005). A research model for mobile phone service behaviors: Empirical validation in the US and Turkey. Journal of Global Information Technology Management, 8(4), $7-28$.

McMaster, T., \& Wastell, D. (2005). Diffusion or delusion? Challenging an IS research tradition. Information Technology and People, 18(4), 383-404.

Meng, D. J., Poslad, S., \& Wang, Y. P. (2009). An intelligent context-aware spatial routing system in mobile environment. In D. J. Meng, S. Poslad, \& Y. P. Wang (Eds.), 5th International Conference on Wireless Communications, Networking and Mobile Computing (pp. 5461-5464), Beijing, PRC.

Middleton, V. T. C., Fyall, A., Morgan, M., \& Ranchhod, A. (2009). Marketing in travel and tourism (4th ed.). Oxford: Butterworth-Heinemann

Netsize. (2010). The Netsize guide by Gemalto: Truly mobile. Retrieved October 2010, from http://www.net size.com/Ressources Guide.htm

Nysveen, H., Pedersen, P., \& Thorbjornsen, H. (2005). Intentions to use mobile services: Antecedents and crossservice comparisons. Journal of the Academy of Marketing Science, 33(3), 330-346.

Pagani, M. (2004). Determinants of adoption of third generation mobile multimedia services. Journal of Interactive Marketing, 18(3), 46-59.

Pedersen, P. (2005). Adoption of mobile internet services: An exploratory study of mobile commerce early adopters. Journal of Organizational Computing and Electronic Commerce, 15(3), 203-222.

Rasinger, J., Fuchs, M., \& Höpken W. (2007). Information search with mobile tourist guides: A survey of usage intention. Information Technology \& Tourism, 9(3/4), 177-194.

Riebeck, M., Stark, A., Modsching, M., \& Kawalek, J. (2008). Studying the user acceptance of a mobile information system for tourists in the field. Information Technology \& Tourism, 10(3), 189-199.
Rogers, E. M. (1995). Diffusion of innovations (3rd ed.). New York: The Free Press.

Salancik, G., \& Pfeffer, J. (1978). A social information processing approach to job attitudes and task design. Administrative Science Quarterly, 23(2), 224-253.

Schepers, J., \& Wetzels, M. (2007). A meta-analysis of the technology acceptance model: Investigating subjective norm and moderation effects. Information \& Management, 44(1), 90-103.

Straub, D., Limayem, M., \& Karahanna, E. (1995). Measuring system usage: Implications for IS theory testing. Management Science, 41(8), 1328-1342.

Tan, E. M-Y., Foo, S., Goh, D. H-L., \& Theng, Y-L. (2009). Tiles: Classifying contextual information for mobile tourism applications. Aslib Proceedings, 61(6), 565-586.

Teo, T., \& Pok S. (2003). Adoption of WAP-enabled mobile phones among Internet users. Omega, 31(6), 483-498.

Venkatesh, V., \& Davis, F. D. (2000). A theoretical extension of the technology acceptance model: Four longitudinal field studies. Management Science, 46(2), 186-204.

Venkatesh, V., Morris, M. G., Davis, G. B., \& Davis, F. D. (2003). User acceptance of information technology: Toward a unified view. MIS Quarterly, 27(3), 425-478.

Wan, Z. (2009). Personalized tourism information system in mobile commerce. Retrieved from http://doi.ieeecomput ersociety.org/10.1109/ICMeCG.2009.123

Wu, J., \& Wang, S. (2005). What drives mobile commerce? An empirical evaluation of the revised technology acceptance model. Information \& Management, 42(5), 719729.

Wu, J., Wang, S., \& Lin, L. (2007). Mobile computing acceptance factors in the healthcare industry: A structural equation model. International Journal of Medical Informatics, 76(1), 66-77.

Yang, K. (2005). Exploring factors affecting the adoption of mobile commerce in Singapore. Telematics and Informatics, 22(3), 257-277.

Yi, M. Y., Jackson, J. D., Park, J. S., \& Probst, J. C. (2006). Understanding information technology acceptance by individual professionals: Toward an integrative view. Information \& Management, 43(3), 350-363. 